\title{
Etiological factors of systemic sclerosis in the southeast region of Romania
}

\author{
CARMEN BOBEICA $^{1 *}$, ELENA NICULET $^{2}$, MIHAELA CRAESCU $^{2}$, ALINA IOANA HALIP $^{1 *}$, \\ IOANA ADRIANA POPESCU ${ }^{1}$, MIRUNA LUMINITA DRAGANESCU ${ }^{3}$, CRISTIAN ONISOR $^{2}$, \\ BOGDAN STEFANESCU ${ }^{4}$ and LAURA GHEUCA-SOLOVASTRU ${ }^{5 *}$
}

\begin{abstract}
${ }^{1}$ Department of Dermato-Venereology, 'Grigore T. Popa' Doctoral School University of Medicine and Pharmacy, Iași 700115; Departments of ${ }^{2}$ Morphological and Functional Sciences, ${ }^{3}$ Clinical Infectious Diseases, and ${ }^{4}$ Clinical Surgery,

'Dunărea de Jos' University, Faculty of Medicine and Pharmacy, Galați 800216; ${ }^{5}$ Department of Clinical Dermato-Venereology,

‘Grigore T. Popa' University of Medicine and Pharmacy, Faculty of Medicine and Pharmacy, Iași 700115, Romania
\end{abstract}

Received September 18, 2020; Accepted October 20, 2020

DOI: 10.3892/etm.2020.9511

\begin{abstract}
Systemic sclerosis (SSc) is a relatively rare autoimmune disease with skin and visceral involvement, having a yet unknown etiopathogenesis. Research has shown that professional exposure to various polluting chemicals such as dyes, aliphatic and aromatic organic solvents, inhalable silica dust or certain heavy metals, can be triggering factors for this disease when they overlap a predisposing genetic profile. Smoking is still a debated factor involved in the etiology of SSc, as authors have divergent opinions on this matter. The present study was designed to analyze the etiological factors identified in the group of 37 patients with diffuse and limited SSc from the southeast region of Romania and the results were compared to the literature data. In the group of patients included in this study, occupational exposure and smoking history were not present in all patients, and a hereditary factor was identified only in an isolated case. The majority of patients suffered from a major negative psychological event or from long-term stressful situations and these factors were associated with smoking history or occupational exposure; this suggests that $\mathrm{SSc}$ is initiated in a set of cumulative triggering factors.
\end{abstract}

Correspondence to: Assistant Professor Dr Elena Niculet or Senior Lecturer Dr Mihaela Craescu, Department of Morphological and Functional Sciences, 'Dunărea de Jos' University, Faculty of Medicine and Pharmacy, 35 Alexandru Ioan Cuza, Galați 800216, Romania

E-mail: helena_badiu@yahoo.com

E-mail: dr.craescumihaela@yahoo.ro

*Contributed equally

Key words: systemic sclerosis, professional exposure, solvents, silica, smoker, pollutants

\section{Introduction}

Systemic sclerosis ( $\mathrm{SSc}$ ) is a rare chronic autoimmune disease with high mortality rates (1). The severity of this disease stems from multiple organ morpho-functional damage with multiple complications: Ulcers, gangrene, pulmonary and myocardial fibrosis, pulmonary hypertension, scleroderma renal crisis, esophageal damage and malabsorption syndrome (2-4). Skin induration in SSc requires differential diagnosis with other sclerodermal diseases $(5,6)$. The pathogenesis of this disease is complex and has many yet uncertain variables, very much similar to the pathogenesis of many neoplasms (7-9). Therefore, it is recognized that a number of triggering environmental factors may overlap with predisposing genetic factors, including occupational exposure to various chemicals including aromatic hydrocarbons, silicates, polyvinyl chloride, drugs (amphetamine, bleomycin, pentazocine), hand vibrations and some infections (10-14). In a 2018 review, Abbot et al concluded that exposure to silicates alone is an important risk factor. Various authors express divergent views concerning exposure to organic solvents (15). In another review, Walecka et al highlighted the role of silicates in the etiology of SSc, but also of multiple organic solvents such as ketones, aromatic and aliphatic hydrocarbons, white spirit solvent for oil-based paints, smoke from welding; underlining the need for protective measures for workers with such occupational exposure. The authors pointed out the lack of clear evidence concerning air pollution involvement in the onset of SSc; the same issue concerns asbestos exposure, heavy metals and silicone implant (16). Occupational exposure raises the issue of introducing SSc to the occupational diseases category. The most common occupational exposure is to silica dust, which induces silicosis, rheumatoid arthritis and lung cancer; the association of silicosis with SSc or mixed connective tissue disease, known under the name of Erasmus syndrome, has also been considered for inclusion in the occupational diseases category. Researchers suggest that SSc associated with silica dust exposure should be included in the occupational diseases category, even when silicosis is not present $(17,18)$. Silicon 
dioxide nanoparticles (nano- $\mathrm{SiO}_{2}$ ) in their amorphous state are microparticles with a diameter of less than $100 \mathrm{~nm}$ and a very low density, which can easily become airborne and inhaled. It seems that nano- $\mathrm{SiO}_{2}$ primarily affects the skin, and through inhalation induces inflammation and lung and cardiovascular toxicity. $\mathrm{Nano}-\mathrm{SiO}_{2}$ toxicity is dependent on the exposure dose, but also on the particle size; the toxicity increases with the decrease of particle size (15-30 nm), being proportionally indirect. $\mathrm{SiO}_{2}$ nanoparticles degrade DNA chains and induce cell apoptosis (19). Among the organic solvents associated with $\mathrm{SSc}$, the most common are aromatic solvents (benzene, toluene, xylene) and trichlorethylene, as well as halogenated solvents. Zhao et al also revealed the significant exposure to ketones (18). Recent studies show that epoxy resins, which are included in the list of occupational toxins, may be involved in the onset of SSc $(17,18,20)$. Not only occupational exposure to toxins poses a risk, but also constant or accidental pollution through water and air contamination with halogenated compounds and aromatic hydrocarbons, such as benzene, xylene and toluene (21). The study on volatile aromatic hydrocarbon toxicity performed by Niculescu and colleagues on laboratory mice reveals some interesting facts. Experimental exposure of laboratory animals to xylene, toluene and benzene registered no clinical signs for chemical toxicity, only a weight increase starting from day 3 of exposure, becoming significant on day 11. This study opens the opportunity for further research in clarifying the toxic profile of these compounds (22). After in-depth analysis of smoking involvement in the onset of SSc, Walecka et al concluded that its role is not clearly supported (16). Although there is no solid evidence that smoking could induce $\mathrm{SSc}$, Hissaria et al revealed that smoking has an adverse effect on disease progression and decreases the survival rate in former and current smoking patients (23).

The present study was designed to analyze the etiological factors identified in the group of 37 patients with diffuse and limited SSc from the southeast region of Romania and the results were compared to the literature data.

\section{Patients and methods}

Patients. We conducted an observational study on a group of 37 patients composed mainly of women $(81.1 \%)$ from urban areas $(64.9 \%)$ The average age of the patients was $54.08 \pm 11,871$ years, with variations between 28 and 76 years. Patients were admitted between February 2019 and March 2020 at the Internal Medicine and Rheumatology Wards of the University Hospital in Bucharest. Patients were diagnosed with SSc using the criteria found in the 2013 American College of Rheumatology (ACR)/European League Against Rheumatism (EULAR) $(24,25)$. Patients with diffuse and limited SSc were included in the study in order to identify the etiological factors involved in the pathogenesis of SSc. Newly diagnosed cases and cases with disease evolution over 10 years were enrolled in the study. The agreement was obtained from the Research Ethics Committee of the Faculty of Medicine in Iasi (24.06.2017) as well as from the Ethics Council of the Clinical Hospital 'St. Maria' in Bucharest (5213/04.04.2019). All procedures in this study are in accordance with the Declaration of Helsinki.
Patient interview. We analyzed the etiological factors that could be involved in the pathogenesis of the disease. Patients were interviewed regarding smoking status, occupational exposure to various polluting chemicals and major psychological events with significant psychological shock or very stressful situations in the period preceding the onset of SSc. The genetic predisposition for ScS from consanguins (ascendants, kin of blood) was also analyzed. Patients were interviewed regarding the presence of SSc in family members, without the possibility of performing genetic studies, as a limitation of the study. The chemicals recorded in the medical literature for the fibrotic potential were targeted, but other toxic substances from the professional environment declared by the patients were also registered. The duration of the exposures was also noted. Patients' statements about the existence of a major traumatic psychological event, which preceded the onset of the disease and which they incriminated as a trigger, was the starting point for interviewing patients. We analyzed the psychological impact of the stressful situation and the way of reporting the patient to the traumatic episode. The evaluation was performed through a structured interview with 4 questions, through which I appreciated: Easy crying, sadness, insomnia and irascibility.

Statistical analysis. The data were obtained by interviewing the patients after they had signed the informed consent and it was introduced into an Excel file. The statistical data processing was carried out using SPSS 24.0 (IBM Corp.) using Microsoft Excel. The quantitative data were characterized through descriptive statistics; the qualitative data were characterized through frequency distributions and contingency tables, and the comparisons between samples were made using the Chi-squared test. All P-values were two-tailed; a P-value of 0.05 was considered significant.

\section{Results}

The group of 37 patients from the south-east region of Romania were introduced in the study, analyzed, and we concluded that only $24.3 \%$ of the investigated patients were exposed to toxic substances and industrial pollutants; no statistically significant differences were observed between the two subtypes of SSc, although the percentage of patients exposed to such toxins was slightly higher in those with limited SSc (28.6\%) as compared to those with diffuse SSc (21.7\%) (Table I, Figs. 1 and 2).

Most patients $(81.1 \%)$ also experienced major traumatic psychological events or suffered psychological shocks; from this perspective, no significant statistical differences were observed between disease subtypes, although the patient percentage was higher among those with diffuse SSc $(87.0 \%)$ as compared to those with limited SSc (71.4\%) (Table I, Figs. 3 and 4).

Regarding the predisposing hereditary background, only one female patient was diagnosed with diffuse SSc and reported that the paternal grandmother suffered from identical symptoms, without mentioning whether she was diagnosed or not with SSc; this indicates the likelihood of SSc being genetically transmitted (Table I, Fig. 5).

Among the patients introduced in this study, $48.6 \%$ were non-smokers; the percentage of smokers to non-smokers being roughly equal (Table II, Figs. 6 and 7). Of those with a 
Table I. Risk factors and frequency distributions-the total group and by subsets.

\begin{tabular}{|c|c|c|c|c|c|c|c|c|}
\hline \multirow[b]{2}{*}{ Risk factors } & \multicolumn{2}{|c|}{ SSc limited } & \multicolumn{2}{|c|}{ SSc diffuse } & \multicolumn{2}{|c|}{ Total } & \multirow[b]{2}{*}{ Chi-square } & \multirow[b]{2}{*}{ P-value } \\
\hline & $\mathrm{n}$ & $\%$ & $\mathrm{n}$ & $\%$ & $n$ & $\%$ & & \\
\hline $\begin{array}{l}\text { Occupational exposure to toxic } \\
\text { substances and pollutants }\end{array}$ & & & & & & & 0.221 & 0.464 (NS) \\
\hline No & 10 & 71.4 & 18 & 78.3 & 28 & 75.7 & & \\
\hline Yes & 4 & 28.6 & 5 & 21.7 & 9 & 24.3 & & \\
\hline $\begin{array}{l}\text { Major psychological events, } \\
\text { psychic shocks }\end{array}$ & & & & & & & 1.368 & $0.228(\mathrm{NS})$ \\
\hline No & 4 & 28.6 & 3 & 13.0 & 7 & 18.9 & & \\
\hline Yes & 10 & 71.4 & 20 & 87.0 & 30 & 81.1 & & \\
\hline Hereditary factors & & & & & & & 0.626 & $0.622(\mathrm{NS})$ \\
\hline No & 14 & 100.0 & 22 & 95.7 & 36 & 97.3 & & \\
\hline Yes & & & 1 & 4.3 & 1 & 2.7 & & \\
\hline Total & & 14 & 100.0 & 23 & 100.0 & 37 & 100.0 & \\
\hline
\end{tabular}

SSc, systemic sclerosis; NS, not significant.

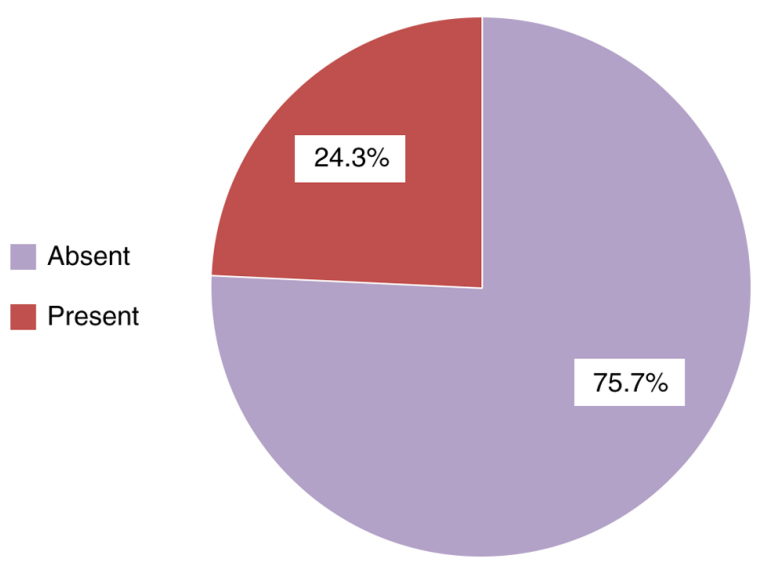

Figure 1. Occupational exposure to toxic substances and pollutants. Total frequency distribution in the total systemic sclerosis (SSc) patient group.

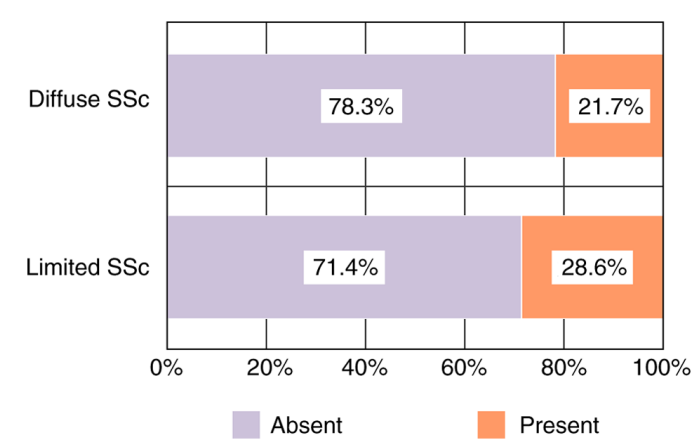

Figure 2. Occupational exposure to toxic substances and pollutants. Frequency distribution by disease subtype. SSc, systemic sclerosis.

smoking addiction, little over a half were categorized as heavy smokers. These percentages were found to be almost similarly in the diffuse SSc patient group; small differences were found in those with limited SSc, having a higher percentage

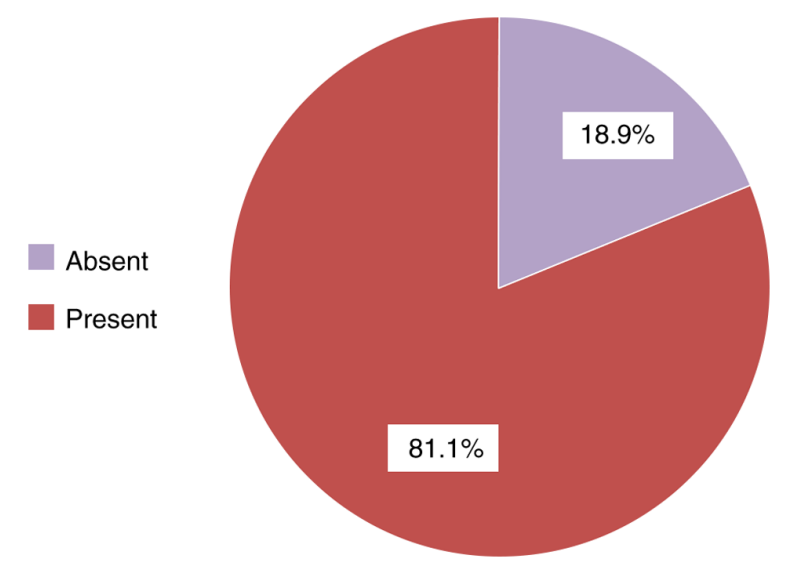

Figure 3. Major traumatic psychological events. The frequency distribution of these events in the total systemic sclerosis (SSc) patient group.

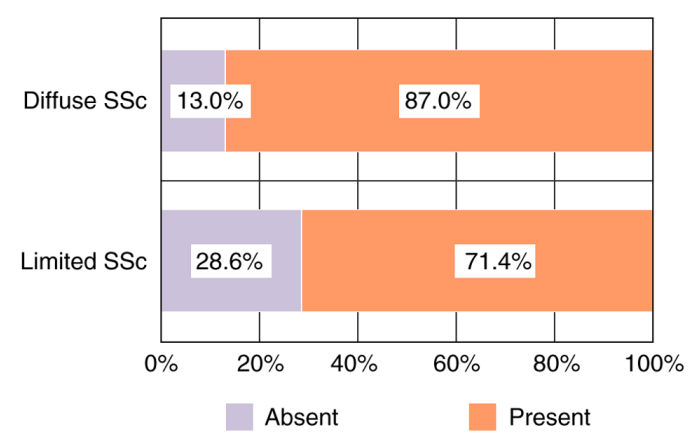

Figure 4. Major traumatic psychological events. Frequency distribution of these events by disease subtype. SSc, systemic sclerosis.

of non-smokers (57.1\%) with equal percentages of smokers to heavy smokers (21.4\% each). An important fact is that only one patient out of the 37 was an active smoker $(2.7 \%)$ and suffered from diffuse SSc (Table II). 
Table II. Group structure by categories of smokers-total and by subsets.

\begin{tabular}{|c|c|c|c|c|c|c|c|c|}
\hline \multirow[b]{2}{*}{ Smoking status } & \multicolumn{2}{|c|}{ SSc limited } & \multicolumn{2}{|c|}{ SSc diffuse } & \multicolumn{2}{|c|}{ Total } & \multirow[b]{2}{*}{ Chi-square } & \multirow[b]{2}{*}{ P-value } \\
\hline & $\mathrm{n}$ & $\%$ & $\mathrm{n}$ & $\%$ & $\mathrm{n}$ & $\%$ & & \\
\hline Smoking history & & & & & & & 0.673 & $0.714(\mathrm{NS})$ \\
\hline No & 8 & 57.1 & 10 & 43.5 & 18 & 48.6 & & \\
\hline Yes-smoker & 3 & 21.4 & 6 & 26.1 & 9 & 24.3 & & \\
\hline Yes-heavy smoker & 3 & 21.4 & 7 & 30.4 & 10 & 27.0 & & \\
\hline Active smoker & & & & & & & 0.626 & $0.622(\mathrm{NS})$ \\
\hline No & 14 & 100.0 & 22 & 95.7 & 36 & 97.3 & & \\
\hline Yes & & & 1 & 4.3 & 1 & 2.7 & & \\
\hline Total & & 14 & 100.0 & 23 & 100.0 & 37 & 100.0 & \\
\hline
\end{tabular}

SSc, systemic sclerosis; NS, not significant.

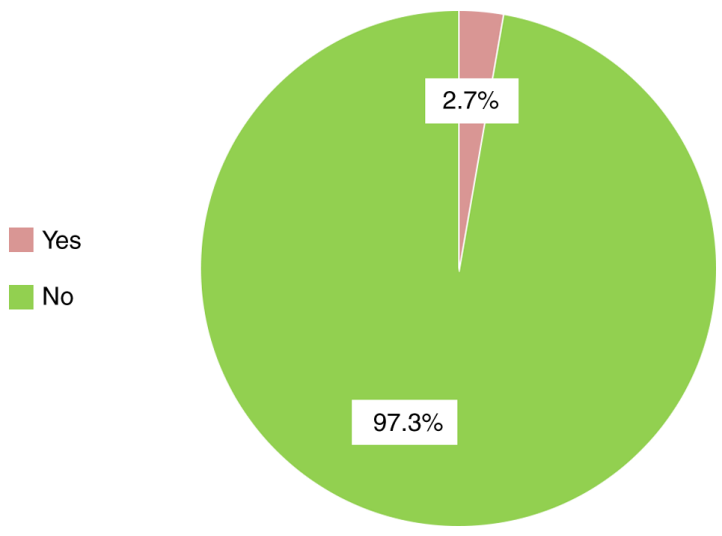

Figure 5. Predisposing genetic background. Frequency distribution in the total systemic sclerosis ( $\mathrm{SSc}$ ) patient group.

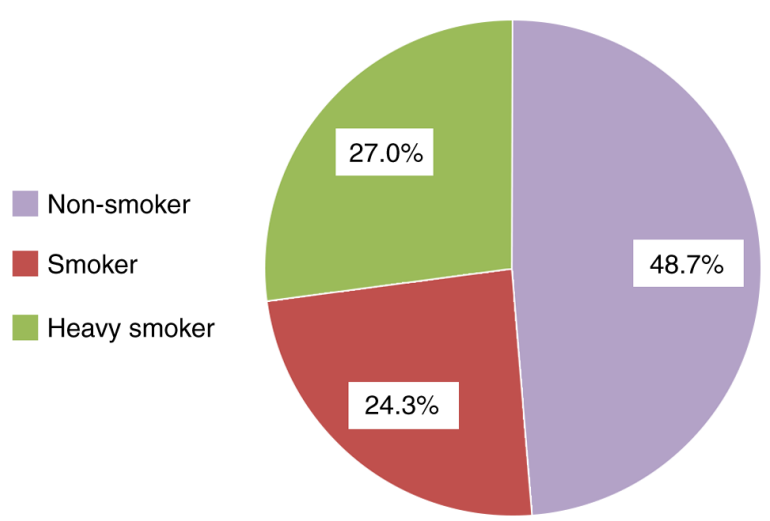

Figure 6. Group structure by smoking addiction in the total systemic sclerosis (SSc) patient group.

\section{Discussion}

This paper is an observational study on a group of patients from the south-east region of Romania, that aimed to identify the etiological factors possibly involved in the pathogenesis of systemic sclerosis $(\mathrm{SSc})$. The number of patients investigated was small due to the low prevalence of this disease. By

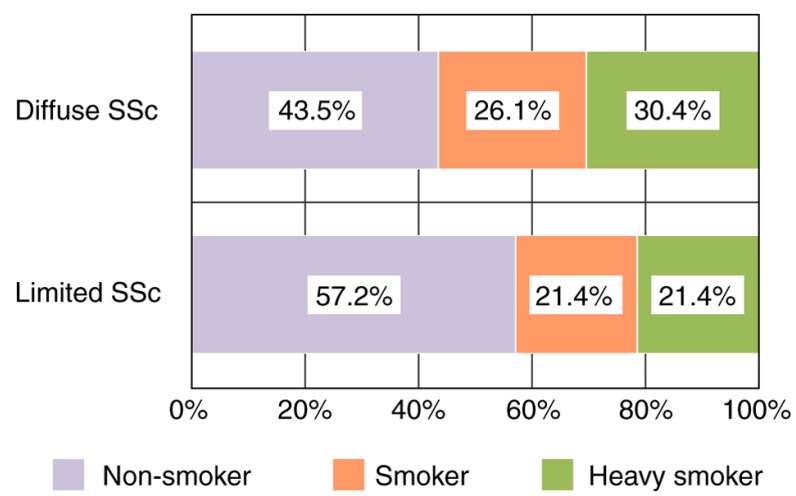

Figure 7. Group structure by smoking addiction. Frequency distribution of the smoking history by disease subtype. SSc, systemic sclerosis.

analyzing occupational exposure to various toxic substances and inhaled pollutants, we found that only a quarter of patients were exposed in their life span for variable time periods of 2 to 5 years or up to 8 consecutive years; the exposure was to organic dyes and solvents such as toluene, xylene and acetonitrile, or to iron oxides and chromium compounds which can be found in synthetic resins used for sound proofing. The patient interviews also identified occupational exposure to hydrogen sulfite, acrolein, aldehydes, benzene, phenols and sulfur dioxide which are released from synthetic rubber, asphalt mixtures, bitumen, diesel and industrial oil. Other exposures identified were to formaldehyde released by pouring plastic into molds, ammonia released from animal manure in the zootechnic field, irritating nitrogen oxide released from pickled feed silos, hydrocyanic acid and isocyanates generated by acrylonitrile and its polymer. All these factors release toxic gases and vapors in the working environment (20). No exposure to respirable crystalline silica powder was identified. Quartz exposure, as a variety of crystalline silica, a well-known factor involved in SSc etiology, was also not found. Among patients exposed to occupational toxic agents, the differences between those with limited and diffuse SSc were not significant. From the remaining patients, a significant percentage of $3 / 4$ (75.7\%) did not register exposure to industrial pollutants. 
Extremely important are the patients' statements regarding major psychological events with psychological shock magnitude and highly extremely stressful life situations which they incriminated as factors that preceded the onset of SSc. Most patients strongly claimed that these events (accidents, illnesses and death of a close person or separation from their life partner) triggered the disease. The ratio of patients who had psychological events as a precursor to the disease was higher among those with diffuse SSc.

By analyzing the SSc predisposing hereditary background, a singular case involving a female patient with diffuse SSc was identified in whom hereditary transmission was from the paternal side without the possibility to perform genetic studies, as a limitation of this study. This observation confirms the role of genetic transmission in the predisposition for SSc, being recognized by many authors (10-14).

Concerning tobacco smoking, half of the patients were smokers and heavy smokers during their lifetime and, with one exception, all were in the process of smoking cessation in the course of this study. The ratio of smokers in the diffuse SSc subtype was slightly higher than that found in those suffering from limited SSc. Our observations suggest that tobacco smoking may be involved in the onset of the disease, especially in diffuse forms of SSc, although the findings are divergent $(16,23)$.

The etiological factors identified were not consistently found among all patients from the analyzed group; Most patients investigated had an episode of traumatic psychological in the past, but smaller proportions of patients had a traumatic psychological event associated with history of smoking or with an occupational exposure or even both.

In conclusion, this autoimmune disorder seems to be caused by a combination of several etiological factors, most often in the background of significant psychological events with traumatic potential. Although the current study managed to reveal some potential etiological factors involved in the etiopathogenesis of SSc, it remains uncertain and requires further research in order to be clarified. The identification of the etiological factors of SSc could allow the issuance of a set of recommendations and the early evaluation of target individuals.

\section{Acknowledgements}

Not applicable.

\section{Funding}

No funding was received.

\section{Availability of data and materials}

The analyzed data sets generated during the present study are available from the corresponding author on reasonable request.

\section{Authors' contributions}

$\mathrm{CB}, \mathrm{EN}, \mathrm{MC}, \mathrm{AIH}$ and LGS were involved in the conception of the study and had major contribution in the writing and revising of the manuscript. IAP, MLD, CO and BS assisted in the acquisition, analysis and interpretation of the data. All authors have read and approved the final manuscript.

\section{Ethics approval and consent to participate}

The present study was approved by the Ethics Review Committees of the Medical University of Iași (24.06.2017) and of the Ethics Council of the Clinical Hospital 'St. Maria' in Bucharest (5213/04.04.2019) and was performed in accordance with the Declaration of Helsinki. All patients provided informed consent and approved the publication of data.

\section{Patient consent for publication}

Not applicable.

\section{Competing interests}

The authors declare that they have no competing interests.

\section{References}

1. Tyndal AJ, Bannert B, Vonk M, Airò P, Cozzi F, Carreira PE, Bancel DF, Allanore Y, Müller-Ladner U, Distler O, et al: Causes and risk factors of death in systemic sclerosis: A study from the EULAR Scleroderma Trials and Research (EUSTAR) database. Ann Rheum Dis 69: 1809-1815, 2010.

2. Denton CP: Advances in pathogenesis and treatment of systemic sclerosis. Clin Med (London) 15 (Suppl 6): S58-S63, 2015.

3. Bobeica C, Vata D, Statescu L, Taranu T, Popescu IA, Grajdeanu AI and Gheuca-Solovastru L: The quality of life for a patient with an autoimmune disease. Bull Integr Psychiatry 25: 27-36, 2019.

4. Bobeica C, Tatu AL, Craescu M and Solovastru L: Dinamics of digital ulcers in systemic sclerosis. Exp Ther Med 20: 61-67, 2020.

5. Tatu AL and Nwabudike LC: The treatment options of male genital Lichen sclerosus et atrophicus: Treatments of genital Lichen sclerosus. In: Proceedings of the 14th National Congress of Urogynecology and the National Conference of the Romanian Association for the Study of Pain. Eforie, Romania, pp262-264, 2017.

6. Tatu AL and Ionescu MA: Multiple autoimmune syndrome type III-thyroiditis, vitiligo and alopecia areata. Acta Endo 13: 124-125, 2017.

7. Noda S, Asano Y, Nishimura S, Taniguchi T, Fujiu K, Manabe I, Nakamura K, Yamashita T, Saigusa R, Akamata K, et al: Simultaneous downregulation of KLF5 and Fli1 is a key feature underlying systemic sclerosis. Nat Commun 5: 5797, 2014.

8. Bobeica C, Craescu M, Ancuta CI, Coman M and Nechita A: Experimental models for the study of systemic scleroderma. Ann 'Dunărea de Jos' Univ Galati 17: 71-84, 2018.

9. Mare LV, Andrese EP, Monu AM, Adam MG, Solovastru L and Vata D: Update on epidemiology of non-melanocyticskin tumors. Rev Chim 70: 3050-3052, 2019.

10. De Martinis M, Ciccarelli F, Sirufo MM and Ginaldi L: An overview of environmental risk factors in systemic sclerosis. Expert Rev Clin Immunol 12: 456-478, 2016.

11. Moraru M, Fulga I, Craescu M, Serban C and Nechita A: Deaths related to psychoactive substances among young youth. A 5-years cross-selectional study in the Legal Medicine Service of Galati, Romania. Ann 'Dunărea de Jos' Univ Galati 1: 87-94, 2017.

12. Modrigan M, Draganescu M, Condratovici Plesea C, Pirvu LL and Condratovici Plesea A: Clinical personality patterns in young adults with HIV nosocomial infection from the region of southeast Romania. Revista de Materiale Plastice 54: 175-179, 2017.

13. Nwabudike LC and Tatu AL: Magistral prescription with silver nitrate and Peru Balsam in difficult to heal diabetic foot ulcers. Am J Ther 25: e679-e680, 2018. 
14. Gheorghe I, Tatu AL, Lupu I, Thamer O, Cotar AI, Pircalabioru GG, Popa M, Cristea VC, Lazar V and Chifiriuc MC: Molecular characterization of virulence and resistance features in Staphylococcus aureus clinical strains isolated from cutaneous lesions in patients with drug adverse reactions. Rom Biotech Lett 22: 12321-12327, 2017.

15. Abbot S, Bossingham D, Proudman S, De Costa C and Ho-Huynh A: Risk factors for the development of systemic sclerosis: A systematic review of the literature. Rheumatol Adv Pract 2: rky041, 2018.

16. Walecka I, Roszkiewicz M and Malewska A: Occupational potential and environmental factors in SSc onset. Ann Agric Environ Med 25: 596-601, 2018.

17. Schmid M, Berset DS, Krief P, Cherix AZ, Danuser B and Rinaldo M: Should systemic sclerosis be recognized as an occupational disease in Switzerland? Swiss Med Wkly 150: w20193, 2020

18. Zhao JH, Duan Y, Wang YJ, Huang XL, Yang GJ and Wang J: The influence of different solvents on systemic sclerosis: An updated meta-analysis of 14 case-control studies. J Clin Rheumatol 22 253-259, 2016

19. Yang X, Liu J, He H, Zhou L, Gong C, Wang X. Yang L, Yuan J, Huang $\mathrm{H}, \mathrm{He} \mathrm{L}$, et al: $\mathrm{SiO} 2$ nanoparticles induce cytotoxicity and protein expression alteration in $\mathrm{HaCaT}$ cells. Part Fibre Toxicol 7: 1,2010 .

20. Magnant J and Diot E: Systemic sclerosis: Epidemiology and environmental factors. Presse Med 35: 1894-1901, 2006.
21. Iordache A, Iordache M, Sandru C, Voica C, Stegarus D, Zgavarogea R, Ionete RE, Cotorcea (Ticu) S and Miricioiu MG: A fugacity based model for the assessment of pollutant dynamic evolution of VOCS and BTEX in the Olt River Basin (Romania). Rev Chim (Bucharest) 70: 3456-3463, 2019.

22. Nicolescu F, Lupu F, Pantea O, Gheorghe CG, Bondarev A and Calin C: Toxicity study of benzene, toluene and xylene (BTX) at exposure on some experimental groups. Rev Chim (Bucharest) 66: 1181-1183, 2015.

23. Hissaria P, Roberts-Thompson PJ, Lester S, Ahern MJ, Smith MD and Walker KG: Cigarette smoking in patients with systemic sclerosis reduces overall survival: Comment on the article by Hudson et al. Arthritis Rheum 63: 1758-1759, 2011.

24. Masi AT and Medsger TA Jr: Progress in the evolution of systemic sclerosis classification criteria and recommendation for additional comparative specificity studies. J Rheumatol 42: 8-10, 2015.

25. van den Hoogen F, Khanna D, Fransen J, Johnson SR, Baron M, Tyndall A, Matucci-Cerinic M, Naden RP, Medsger TA Jr, Carreira PE, et al: 2013 classification criteria for systemic sclerosis: An American college of rheumatology/European league against rheumatism collaborative initiative. Ann Rheum Dis 72: 1747-1755, 2013.

This work is licensed under a Creative Commons Attribution-NonCommercial-NoDerivatives 4.0 International (CC BY-NC-ND 4.0) License. 